Bioscientia Medicina: Journal of Biomedicine \& Translational Research

Journal Homepage: www.bioscmed.com

\title{
Penetrating Facial Injury by Motorcycle Gear Shifter Lever: A Case Report Welli Zulfikar ${ }^{*}$, Arip Heru Tripana ${ }^{2}$
}

${ }^{1}$ Head and Neck Surgeon, Surgery Department, Arifin Achmad General Hospital, Riau, Indonesia

${ }^{2}$ Surgical Resident of Medical Faculty, Riau University/Arifin Achmad General Hospital, Riau, Indonesia

\section{A R T I C L E I N F O \\ Keywords: \\ Facial Injury \\ Penetrating wound \\ Motorcycle gear shifter lever}

*Corresponding author:

Welli Zulfikar

\section{E-mail address:} wellywz@yahoo.com

All authors have reviewed and approved the final version of the manuscript.

https://doi.org/10.37275/bsm.v6i4.494

\begin{abstract}
A B S T R A C T
Background. Penetrating facial injury can cause injury to the bone and soft tissue surrounding. Penetrating facial injury caused by organic foreign bodies or metal material increases the risk of infection in the wound. Identification of the location of the entry of foreign bodies, whether the vital organs, the presence of injury to the nerves, vascular, visual, and other muscle damage is very important to do. For that immediate and optimal treatment can be applied to reduce morbidity and mortality. Case presentation: A 13 years old boy arrived in ER admission with penetrating facial injuries. A corpus alienum penetrated the patient's face at the medial meatus of the right eye along with bleeding from the nose and around the wound. Evaluation and management of the penetrating facial injury were performed in accordance with the ATLS protocol. The aim of management in penetrating facial injuries is to remove the foreign body with minimal trauma to surrounding structures and to maintain normal function and optimal appearance. The patient underwent emergency surgery the remove corpus alienum and wound exploration under general anesthesia. Postoperative evaluation shows no bleeding or signs of infection, no visual impairment, and tear flow were found. Conclusion: Penetrating facial injury due to motorcycle gear shifter lever is rare. Good Management of penetrating facial injury will give satisfactory results.
\end{abstract}

\section{Introduction}

Penetrating trauma is defined as an injury caused by a foreign body penetrating the skin or mucosa and entering through the body. Penetrating facial trauma is a rarely reported case. ${ }^{1}$ Projectile penetrating trauma to the face is most commonly caused by gunshots while non projectile penetrating trauma is most commonly caused by knives, shards of glass, screwdrivers, or tree branches. ${ }^{1,2}$

Penetrating trauma to the face can cause injury to the surrounding bone and soft tissue. ${ }^{3}$ Penetrating facial trauma is a complex case because there are important facial structures that need to be treated immediately and carefully. Penetrating trauma to the face by organic foreign bodies or metal materials pose a risk of causing the wound to become infected.1,2,4
The initial management of patients with penetrating trauma can be challenging and requires a comprehensive understanding and multidisciplinary approach. Resuscitation especially airway management, has to be carried out immediately. ${ }^{2}$ Inspection at entrance wound of foreign bodies, whether it causes injury to the nerves, vascular, visual, and surrounding muscles should be identified carefully. Prompt and appropriate treatment can significantly reduce morbidity and mortality. ${ }^{1,3,5}$ In this case report, we present a case of penetrating trauma to the face due to the motorcycle gear lever. 


\section{Case Presentation}

A 13-year-old boy was admitted to the emergency department of Arifin Achmad General Hospital with a condition of a foreign body (motorcycle gear lever) had been stuck and penetrated the right side of his face for 3 hours before he was admitted to the hospital.

The patient rode a motorcycle crossed an emergency pedestrian bridge in the form of a board measuring 600 $\mathrm{x} 20 \times 2 \mathrm{~cm}$ which was used as a means to cross a small river. While crossing the river, the patient slipped so that the patient and the motorcycle he was riding fell into the river. When the patient was evacuated, the motorcycle gear lever was found stuck in the patient's face. Help was carried out by the surrounding community by removing the gear from the motorcycle. Patient was taken to the local health center and then referred to Arifin Achmad Hospital with the motorcycle gear lever still stuck in the patient's face. The patient was conscious and had no signs of head injury.
The initial management of the patient was primary survey. Airway management, breathing, and circulation in accordance with the guidelines for advanced life support (ATLS) were observed. The airway was adequate and 2 liters/minute was given to the patient. After confirming that airway is secure, the next step was an evaluation of breathing and circulation, then proceed with secondary survey.

Based on the results of physical examination, patient's face was penetrated by a foreign body in the form of a motorcycle gear lever stuck in the face located on the area of right eye. Bleeding showed from the nose and around the wound. The patient's mouth and oropharynx were normal (Figure 1). 3D Head CT scan performed and showed a foreign body penetrated from the medial right nasal bone to the maxillary bone and caused a fragmented fracture on the right maxillary bone (Figure 2).

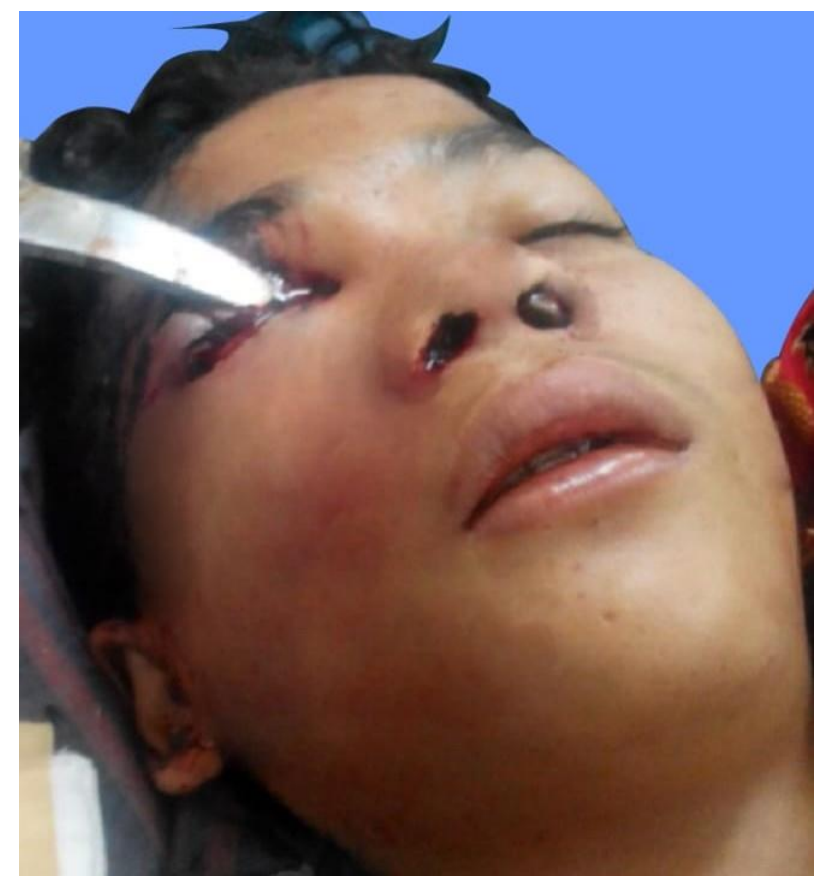

Figure 1. The position of the motorcycle gear lever that penetrates the face

\section{Surgery Procedure}

Patient underwent emergency surgery under general anesthesia to remove a foreign body. The patient is positioned in the supine position with the head hyperextended. After that, aseptic and antiseptic procedures were carried out. The incision starts from the inferior orbital margin and continues to the lateral margin of the nasal cavity. Next, an osteotomy was performed on the maxillary bone around the corpus alienum, and exploration was carried out by tracing the corpus alienum. The corpus alienum penetrates from the maxillary bone to the sphenoid sinus.from corpus 
alienum the tissue and bone (Figure 3). Then the corpus alienum continued with repair nasolacrimal duct using IV catheter no. 18 and close the defect by placing the maxillary bone back using the plate screws. The wound is then closed layer by layer. The skin closure was sutured using proline 5.0 thread (Figure 4).
Patients are given adequate antibiotics and tetanus prophylaxis to prevent the risk of infection in the wound. Postoperative evaluations were carried out for signs of bleeding and infection.
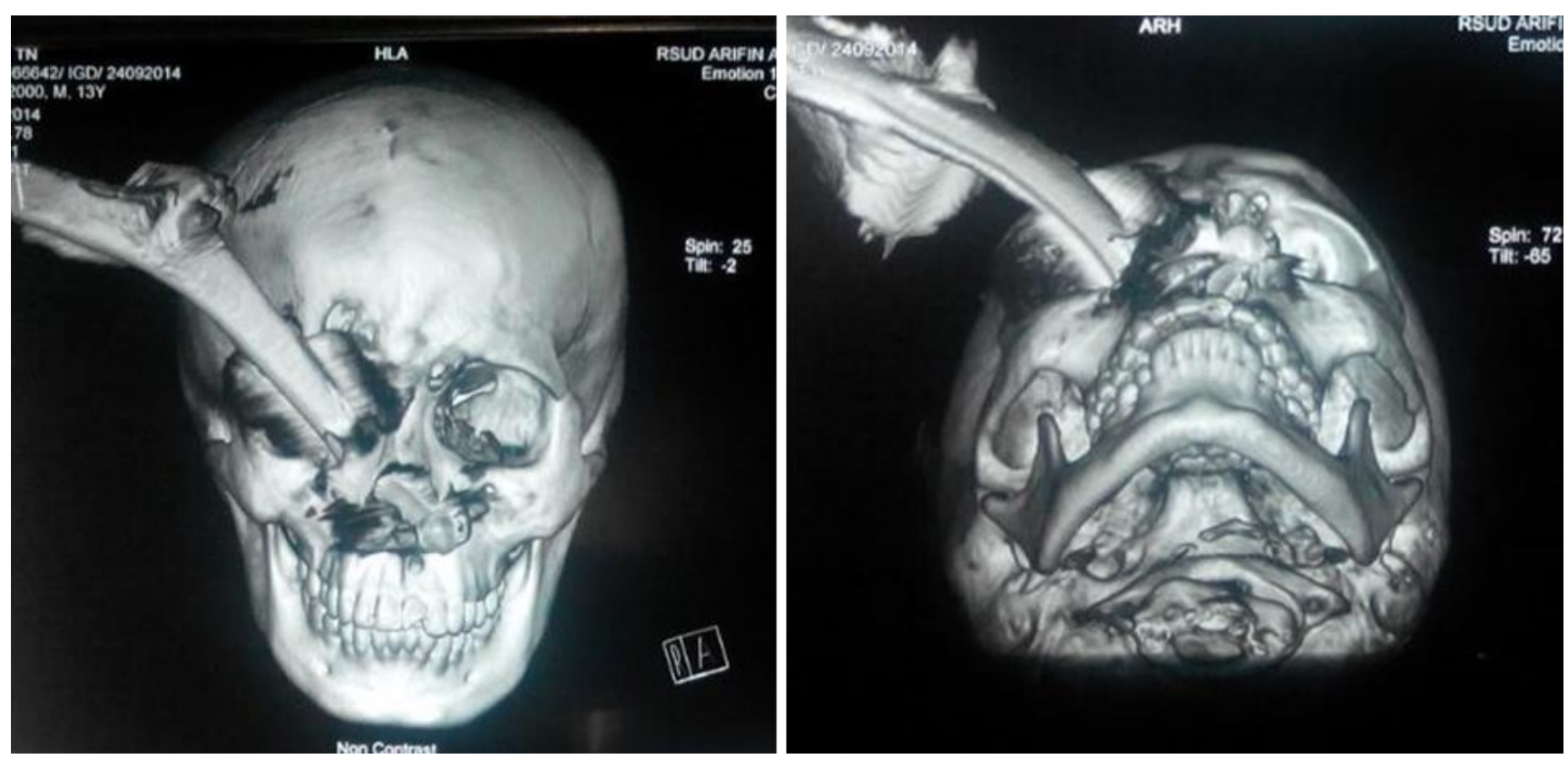

Figure 2. 3D CT scan show that the corpus alienum penetrates the face and causes fractures of the nasal and maxillary bones

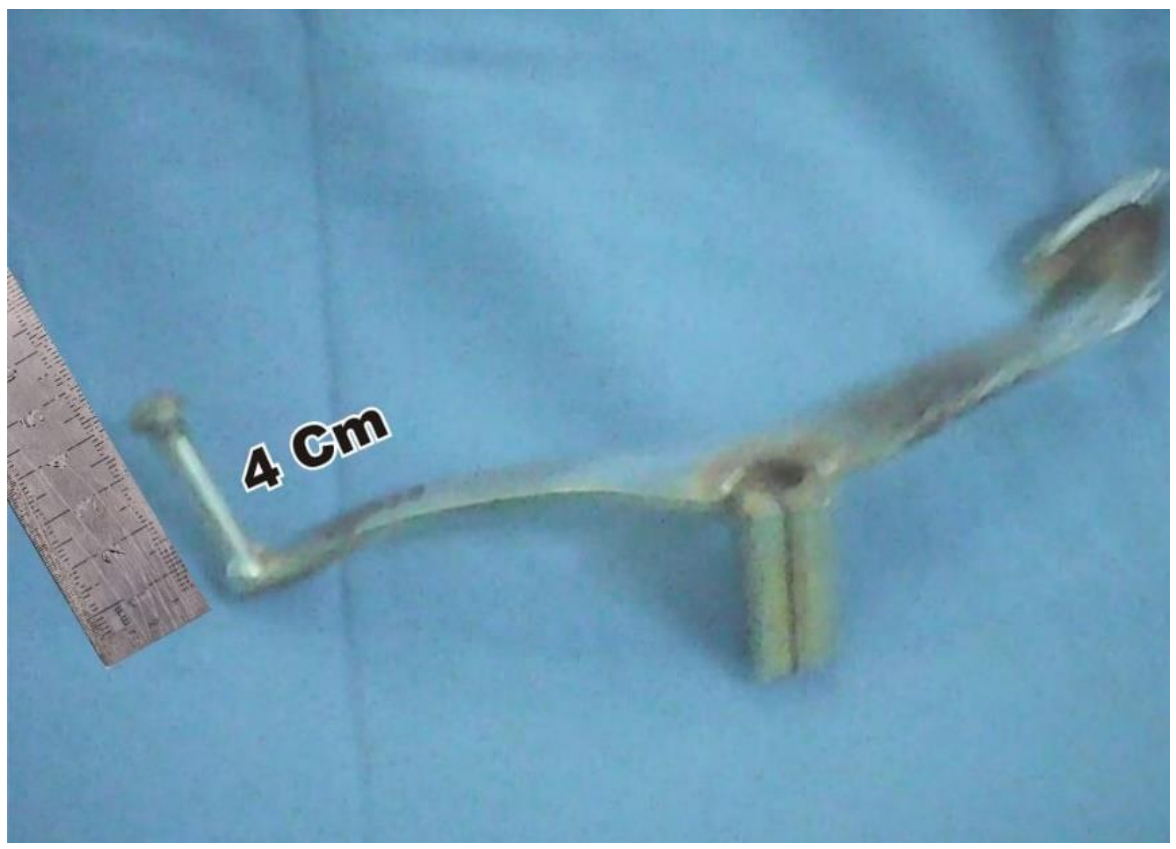

Figure 3. Motorcycle gear shifter lever 


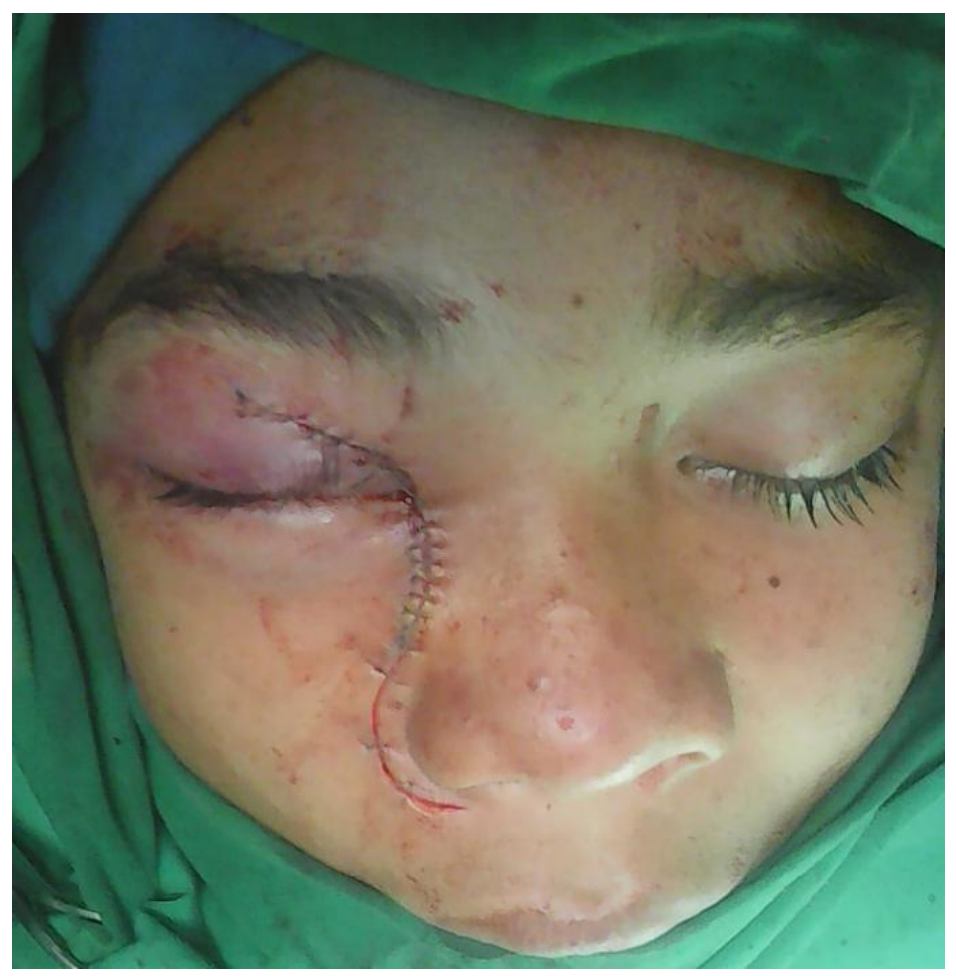

Figure 4. Post operative picture

\section{Discussion}

Penetrating trauma to the face causes high rates of morbidity and mortality. Previous studies have stated that penetrating trauma to the face has a higher risk of having accompanying injuries with a risk percentage ranging from 50 to $80 \%$. Trauma to the bones of the upper face and maxilla is often associated with other intracranial injuries. ${ }^{3}$ It is known that there is a lot of literature that focuses on cases of penetrating trauma to the neck, chest, and abdomen, but there are only a few written reports and literature that examine penetrating trauma to the face, especially in Southeast Asia. ${ }^{5}$

Face is an important part of the human body in both functional and aesthetic aspects. Facial trauma is feared to endanger important anatomical functions such as breathing, eating and drinking, vision, smell, and expression. Maxillofacial trauma demands optimal management of both functional and cosmetic aspects. Motamedi et al explained that there are several things that will affect the postoperative outcome of facial trauma, including the general condition of the patient, the time and duration of the operation, the level of tissue damage, and the use of appropriate surgical instruments. 6 Overall, in this case, there was no significant functional impairment and the outcome was satisfactory.

Penetrating trauma to the face can cause serious airway and breathing problems. Swelling or excessive bleeding may occur later in life causing airway. The evaluation of penetrating maxillofacial trauma should follow the ATLS protocol with the primary importance of assessing the airway, breathing, and circulation. In this case the patient's airway lever gear motor canthus to the maxillary sinus, so it did not interfere with the airway and this facilitated the intubation process at the time of surgery.

Penetrating facial trauma involving the eyelids and periorbital should be thoroughly assessed immediately. Injuries to the margin eyelid injury caused by the gear injured part of the nasolacrimal duct so that it requires an optimal repair to avoid future complications. Lacerations on the medial eyelid are at risk of causing a discontinuity of the lacrimal canaliculi, especially in cases of lacerations with vertical direction towards the lacrimal punctum. Deep horizontal lacerations can also interfere with the canaliculi but are less common. ${ }^{7}$

Repair of the nasolacrimal duct was performed using an IV catheter No. 18 by identifying punctum the upper and lower nasolacrimal duct then creating a path 
along the floor of the orbital through the inferior orbital fissure to the inferior nasal meatus. Motorcycle lever gear is made of metal which is easily contaminated by bacteria. The removal of the foreign object has to be done immediately followed by administration of ATS and antibiotics to reduce the infection rate in these cases.

In this case, the patient with a penetrating gear surgery emergency to remove the foreign body. Wound care within the first 48 hours with intense management of all definitive aspects of the injury is necessary. The goal of primary treatment is to repair the wound. Either hard or soft tissue and all major wound areas are repaired. Wound debridement and irrigation are performed to prevent foreign body retention in the trauma area.

Incorrect removal of a foreign object can cause lifethreatening bleeding because a foreign object could injure large blood vessels, so that bleeding was restrained, therefore the removal of a foreign body has to be explored carefully to make sure the blood vessels were not injured. In this case, there were no signs of injuries to major blood vessels such as active bleeding, extensive hematoma, bruising, and decreased pulse function. The goal of surgery is to remove the foreign body with minimal injury to surrounding structures. In particular, the management of facial trauma is to restore normal function and appearance.

Parenteral antibiotics and tetanus prophylactic were given to prevent the risk of wound infection. An in-depth examination of the patient starting from the history, physical examination, radiological examination, appropriate decision making, appropriate treatment, and good follow-up applied to achieve optimal treatment results. Multidisciplinary management is key in such cases because of the vital anatomic structures of the craniofacial region and cranial base. Delayed treatment may increase the risk of infection and soft tissue swelling, obscure landmarks, and make it more difficult for the operator to define the precise boundaries of the traumatic lesion. ${ }^{8}$

According to Gordin et al, facial paralysis can occur, one of which is due to trauma to the face such as penetrating wounds to the face. Electroneurography and electromyography are the recommended tests to detect facial paralysis. ${ }^{9}$ However, this was not done in this case due to the unavailability of the required facilities. Patients were educated about signs of possible complications in epiphora, mucopurulent discharge from the punctum, pain in the lacrimal sac, cellulitis in the orbital area, and dacryocystitis. ${ }^{10}$

\section{Conclusion}

Penetrating trauma to the face due to motorcycle gear lever is a rare case, but was a potentially lifethreatening condition that requires appropriate management, because there are several important structures, such as blood vessels, nerves, nasolacrimal duct, and other relatively small structures. Contamination that may be present in the gear motor lever also poses a risk of infection, therefore antibiotic treatment and prophylactic tetanus are given to reduce the risk of infection.

The patient in this case underwent an emergency to remove the foreign body and explore the wound under general anesthesia, to remove the corpus alienum lever gear motor repair nasolacrimal duct. Postoperative evaluation did not found any bleeding or signs of infection. Management of the nasolacrimal duct is performed by insertion of a drain and evaluated for 1 week to ensure satisfactory results.

\section{References}

1. Tombeng MA, Prasetyo E, Lumintang NA, Oley MC. Penetrating facial injury by a tree branch: A case report. J Biomedik. 2019; 11(2): 85.

2. Wang K, Shah KB, Rajagopalan S. Airway management of penetrating facial trauma from an impaled screwdriver: A case report. Glob J Anesth Pain Med. 2020; 3(5): 319-22.

3. Scheyerer MJ, Döring R, Fuchs N, Metzler P, Sprengel K, Werner CML, et al. Maxillofacial injuries in severely injured patients. J Trauma Manag Outcomes [Internet]. 2015; 9(1): 1-9. Available

from:

http:/ /dx.doi.org/ 10.1186/s 13032-015-00252 
4. Payami A, Montazem AH. Management of penetrating maxillofacial trauma as a result of industrial accident: Report of an unusual case. Craniomaxillofacial Trauma Reconstr Open. 2020; 5: 247275122094941.

5. Arif MZ, Rajanikanth BR, Prasad K. Soft Tissue injuries of the maxillofacial region occurring from motorcycle accidents. J Maxillofac Oral Surg [Internet]. 2019; 18(3): 432-9. Available from: https://doi.org/10.1007/s12663-0181149-5

6. Motamedi MHK. An assessment of maxillofacial fractures: A 5-Year Study of 237 Patients. 2003; (11): 61-4.

7. Donald PJ, Holt GR. Resident manual of trauma to the face, head, and neck. 1st ed. Holt GR, editor. Virginia: American Academy of Otolaryngology-Head and Neck Surgery Foundation; 2012; 51-70

8. Sadek EY, Elbarbary A, Safe II. Periorbital trauma: A new classification. craniomaxillofacial trauma reconstr. 2019; 12(3): 228-40.

9. Gordin E, Lee TS, Ducic Y, Arnaoutakis D. Facial nerve trauma: Evaluation and considerations in management. 2015; 1(212).

10. Segal KL, Tsiouris AJ, Lelli GJ. Trauma Lacrimal Sac and Nasolacrimal Duct. Encycl Ophthalmol. 2016; 1-4. 